Individual Differences and Changes in Self-Reported Work Performance During the Early Stages of the COVID-19 Pandemic

\author{
Hannes Zacher ${ }^{1}$ \\ Cort W. Rudolph ${ }^{2}$ \\ Melina Posch ${ }^{1}$ \\ ${ }^{1}$ Institute of Psychology - Wilhelm Wundt, Leipzig University \\ ${ }^{2}$ Department of Psychology, Saint Louis University
}

This is a post-review, pre-print version of a paper accepted for publication at Zeitschrift für Arbeits- und Organisationspsychologie. For the final, proof-read version, please refer to the journal: https://www.hogrefe.com/de/zeitschrift/zeitschrift-fuer-arbeits-undorganisationspsychologie

Please cite as:

Zacher, H., Rudolph, C. W., \& Posch, M. (2021, in press). Individual differences and changes in self-reported work performance during the early stages of the COVID-19 pandemic. Zeitschrift für Arbeits- und Organisationspsychologie.

Correspondence concerning this article may be addressed to:

Prof. Dr. Hannes Zacher

Leipzig University

Institute of Psychology - Wilhelm Wundt

Neumark 9-19

04109 Leipzig

hannes.zacher@uni-leipzig.de

\title{
Funding
}

The study reported in this article is funded by Volkswagen Foundation (Az. 96 849-1, "Work and Health in the Time of COVID-19: A Longitudinal Study"). 


\begin{abstract}
The goal of this longitudinal study was to examine how three dimensions of self-reported work performance, including task proficiency, adaptivity, and proactivity, changed between December 2019 and September 2020 in Germany. Based on event system and transition theories, we expected work performance to decline due to the "lockdown" between early April and early May 2020, and to subsequently increase when restrictions were eased between early May and early September 2020. Additionally, we hypothesized that high levels of core self-evaluations (i.e., employees' fundamental evaluations about themselves) buffer the decline and strengthen the recovery in work performance. Data were collected from $N=591$ full-time employees across eight measurement points. Results based on discontinuous latent growth curve modeling largely supported the expected trajectories in work performance. Moreover, core self-evaluations positively predicted the levels of work performance, as well as the slopes indicating recovery in task proficiency and adaptivity, but not proactivity.

Keywords: COVID-19; pandemic; work performance longitudinal study; core self-evaluations
\end{abstract}

\title{
Zusammenfassung
}

Individuelle Unterschiede und Veränderungen in selbstberichteter Arbeitsleistung während der frühen Phasen der COVID-19 Pandemie

Das Ziel dieser Längsschnittstudie ist es zu untersuchen, wie sich drei Dimensionen der selbsteingeschätzten Arbeitsleistung (Aufgabenleistung, Adaptivität und Proaktivität) zwischen Dezember 2019 und September 2020 in Deutschland verändert haben. Basierend auf der Event System Theory und Transition Theories wurde angenommen, dass die Arbeitsleistung aufgrund des „Lockdowns“ zwischen Anfang April und Anfang Mai 2020 abgenommen hat, und dass die Arbeitsleistung anschließend wieder zugenommen hat als Einschränkungen zwischen Anfang Mai und Anfang September 2020 schrittweise aufgehoben wurden. Weiterhin wurde angenommen, dass hohe Zentrale Selbstbewertungen (Core Self-Evaluations; d.h. fundamentale Bewertungen des eigenen Selbst) die Abnahme in Arbeitsleistung abschwächen und die Erholung in Arbeitsleistung verstärken. Daten wurden von $N=591$ Vollzeit-Erwerbstätigen zu acht Messzeitpunkten erhoben. Ergebnisse basierend auf Discontinuous Latent Growth Curve Modeling zeigten weitestgehend Unterstützung für die angenommenen Veränderungen in der Arbeitsleistung. Weiterhin sagten Zentrale Selbstbewertungen generelle Arbeitsleistung sowie die Zunahme in Aufgabenleistung und Adaptivität, aber nicht in Proaktivität, positiv vorher. Schlüsselwörter: COVID-19; Pandemie; Arbeitsleistung; Längsschnittstudie; zentrale Selbstbewertungen 


\section{Individual Differences and Changes in Self-Reported Work Performance During the Early Stages of the COVID-19 Pandemic}

Since December 2019, the COVID-19 pandemic has significantly affected the lives and work experiences of many people around the globe. A number of longitudinal studies have already shown that the pandemic has impacted various important employee outcomes, such as feelings of exhaustion (Meyer et al., 2021) and subjective well-being (Zacher \& Rudolph, 2021b). However, we currently lack knowledge on potential changes in work performance (i.e., actions that contribute to organizational goals; Campbell \& Wiernik, 2015) across the early stages of the pandemic. This is unfortunate, because work performance is an important individual outcome that is associated with indicators of employee career success (e.g., salary, promotions; $\mathrm{Ng} \&$ Feldman, 2010) and firm-level outcomes (e.g., product quality, financial performance; Asgari et al., 2021). Moreover, work performance varies dynamically "within employees" over time (Dalal et al., 2014) and can be influenced by disruptive events in the workplace and beyond (Morgeson \& DeRue, 2006). We also currently do not know which individual difference characteristics may have buffered decreases in work performance due to significant events associated with the COVID-19 pandemic, and which individual characteristics may aid subsequent increases in work performance. In other words, we lack evidence on factors that contribute to employee resilience (see Hartmann et al., 2020) in terms of performance maintenance and recovery during the pandemic.

The goals of this longitudinal study, therefore, are twofold. First, we examine how three dimensions of self-reported work performance, including task proficiency, adaptivity, and proactivity, changed between December 2019 and September 2020. This time period covers the

early stages of the COVID-19 pandemic in Germany (for a timeline, see Figure A1 in the online 
appendix, https://osf.io/n2m79/?view_only=eb32691880db4f199cef2ff9ad03861e). Task

proficiency, adaptivity, and proactivity are considered particularly important in contemporary workplaces characterized by uncertainty and interdependence (Griffin et al., 2007). Moreover, there is a consensus in the literature that these work performance dimensions reflect important behaviors across different jobs (Campbell \& Wiernik, 2015). Self-reports of work performance capture how employees perceive and evaluate their own actions at work. Meta-analyses show that self-reports are moderately and positively associated with supervisor and peer ratings of work performance ( $\rho$ s between .34 and .36; Harris \& Schaubroeck, 1988; Heidemeier \& Moser, 2009).

Based on event system and transition theories (Bliese et al., 2017; Morgeson et al., 2015; Schlossberg, 1981), we expect that task proficiency, adaptivity, and proactivity dropped due to the first national lockdown due to the COVID-19 pandemic in Germany between early April and early May 2020, and subsequently increased when restrictions were progressively lifted between early May and early September 2020. Figure 1 illustrates the expected trajectories in the three forms of work performance over time. We did not expect differential trajectories for the three work performance dimensions. Instead, we included the three dimensions to replicate potential changes induced by the lockdown across multiple forms of work performance.

\section{PLEASE INSERT FIGURE 1 HERE}

The second goal of our study is to examine the role of individual differences in core selfevaluations for the predicted trajectories in work performance during the early stages of the COVID-19 pandemic. Specifically, we propose that high levels of core self-evaluations buffer the declines in work performance due to the lockdown and strengthen the recovery in work performance in the months following the lockdown. Core self-evaluations refer to individuals' 
fundamental evaluations about themselves, including their abilities, achievements, control, and worth (Judge et al., 1997). Thus, core self-evaluations and its components are conceptually highly relevant for work performance outcomes. Research shows that core self-evaluations are positively related to work performance (Judge \& Bono, 2001) and to the use of effective coping strategies (Kammeyer-Mueller et al., 2009).

We contribute to the work and organizational psychology literature in two important ways. First, we extend organizational theory and research on events and transitions by examining within-person changes in work performance during the early stages of the COVID-19 pandemic, with a focus on the effects of the first national lockdown in Germany. Scholars have suggested that event system and transition theories are useful for studying the transition and recovery processes associated with strong events that are novel, disruptive, and critical, such as terrorist attacks or natural catastrophes (Bliese et al., 2017; Morgeson et al., 2015). So far, only few studies have demonstrated effects of such events on work-related experiences and behaviors, and particularly longitudinal studies with multiple assessments before and after the events are rare (e.g., Bacharach \& Bamberger, 2007; Hochwarter et al., 2008).

Second, we advance the literature on the beneficial role of core self-evaluations for workrelated outcomes, including work performance (Erez \& Judge, 2001; Judge, 2009), by investigating how this individual difference characteristic relates to within-person changes in work performance over time. Most research has adopted a static approach by examining between-person differences in both core self-evaluations and work outcomes (for an exception, see Judge \& Hurst, 2008). We also contribute to research on the meta-concept of resilience (Hartmann et al., 2020) by exploring whether individuals with higher (vs. lower) core selfevaluations experience a weaker decline in work performance due to the lockdown and a 
stronger recovery in work performance in the months following the lockdown.

\section{Event System and Transition Theories}

Event system theory constitutes an integrated theoretical framework that aims to explain the nature of events and their consequences over time and within and across multiple hierarchical levels, ranging from the broader societal level to the individual level (Morgeson et al., 2015). The theory defines events as discrete (i.e., bounded in time and space), discontinuous (i.e., nonroutine), and observable circumstances or actions in the environment (i.e., external to employees; Morgeson et al., 2015). An event system entails the interaction of event strength, space, and time. First, the theory suggests that event strength, or the likelihood that the event becomes salient and leads to changes in employee behavior, is based on the extent to which the event is novel (i.e., a new or unexpected phenomenon), disruptive (i.e., a clear discontinuity in the environment), and critical (i.e., important, commanding attention; Morgeson et al., 2015). For example, the $9 / 11$ terrorist attacks can be considered a strong event that led to various changes in organizational and employee behavior. Second, the notion of event space entails that events occur in a specific location and hierarchical level (e.g., society, organization, team, individual); effects of events that originate at a certain hierarchical level can affect behavior at a higher, lower, or the same level (Morgeson et al., 2015). For instance, the installment of a new and wellknown company chief executive officer may impact employee behavior within the company, but this event may also lead to changes in the wider industry. Importantly, event system theory predicts that novel, disruptive, and critical events are more likely to change behaviors when they occur at higher (e.g., country) versus lower (e.g., team) levels, and when they have an impact on a larger (vs. smaller) number of different levels (Morgeson et al., 2015). Finally, event time refers to the timing of an event and how long its effects last. Event system theory proposes that 
novel, disruptive, and critical events are more likely to change behaviors when they have a longer (vs. shorter) duration and when their strength increases over time (Morgeson et al., 2015). Transition theories complement event system theory in that they describe and explain the processes that take place before and after individuals are exposed to an event (Bliese et al., 2017). According to Schlossberg (1981), a transition occurs "if an event or nonevent results in a change in assumptions about oneself and the world and thus requires a corresponding change in one's behavior and relationships" (p. 5). Similarly, crisis theory proposes that a crisis is a "relatively short period of disequilibrium in which a person has to work out new ways of handling a problem" (Moos \& Tsu, 1976, p. 13). Thus, crises or transitions entail events that have significant consequences for human behavior. Schlossberg (1981) further defined adaptation to a transition as "a process during which an individual moves from being totally preoccupied with the transition to integrating the transition into his or her life" (p. 7). Schlossberg (1981) argued that the extent to which individuals adapt successfully to a transition depends on the interplay between the characteristics of external events and individual difference characteristics, the latter including, for example, "the individual's sense of competency" (p. 8) and "a moderately favorable self-evaluation, an internal locus of control ..., and a sense of responsibility" (p. 12).

More recently, Bliese and colleagues (2017) outlined a methodologically based framework on transitions to advance theory and research on the patterns of changes in employee outcomes due to an event, the discontinuous growth model (see also Bliese \& Lang, 2016). The discontinuous growth model has three parameters: (1) the pre-event covariate $\left(\mathrm{TIME}_{\mathrm{pre}}\right)$ that represents the pretransition slope, or the trajectory of an outcome before the event; (2) the transition covariate (TRANS) that represents the contrast between the values in the outcome before and immediately 
after the event; and (3) the recovery covariate (RECOV) that represents the trajectory of the outcome (i.e., increases or decreases) after the event (Bliese et al., 2017; see Figure 1). The discontinuous growth model further allows examining individual difference predictors of each of these three parameters. Specifically, individuals with certain levels in an individual difference characteristic may show stronger or weaker increases or decreases in the outcome in the period before encountering the event, upon encountering the event, and/or during the post-transition period. Accordingly, Bliese and colleagues (2017) suggest that their framework may also contribute to a better understanding of the meta-concept of resilience, which refers to the process of successful adaptation in a context characterized by adversity (Hartmann et al., 2020).

\section{Declines in Self-Reported Work Performance Due to the Lockdown}

Work performance refers to measurable actions that contribute to organizational goals, and it encompasses different dimensions (Campbell \& Wiernik, 2015). Traditionally, research has focused on task proficiency, which refers to the extent to which employees meet the formal expectations and requirements of their work role (Griffin et al., 2007). Task proficiency can be assessed with regard to aspects of a work role that are clearly defined and formalized, whereas other forms of work performance involve aspects of a work role that cannot be clearly formalized and involve more discretion and uncertainty. In particular, adaptivity refers to behaviors an employee shows to adapt to changes in the work system or role; it entails the extent to which employees respond to, cope with, and support these changes (Griffin et al., 2007). Proactivity represents the degree to which employees show self-starting and future-oriented behaviors to initiate positive changes in their work environment, work role, or themselves, such as improving work methods (Griffin et al., 2007).

Based on event and transition theories, we hypothesize that task proficiency, adaptivity, and 
proactivity declined between early April 2020 and early May 2020 due to the lockdown in Germany. This event began at the end of March 2020 and lasted until the beginning of May 2020 (Figure A1 in the online appendix). It involved severe restrictions to public and business life (e.g., leaving one's home only for important reasons, such as work or grocery shopping; ban of public events and private parties; work from home orders), interpersonal contact restrictions (e.g., physical distancing; only two people were allowed to meet in public), as well as the closures of daycares, schools, and hygiene businesses (e.g., hair cutters, massage services, beauty salons, tattoo parlors).

Based on event system theory (Morgeson et al., 2015), the first national lockdown in Germany can be characterized as a highly novel, disruptive, and critical event that resided at the country level and likely had strong top-down effects on organizations, teams, and individual employees, as well as employees' families. Event system theory suggests that such strong events command people's attention, impact their cognitive processing, and change their established behavioral routines (Morgeson, 2005; see Propositions 1-3 in Morgeson et al., 2015). The lockdown was novel, disruptive, and critical, as most people in Germany had not experienced comparably severe restrictions in their daily lives and disruptions of their work routines before.

The strong novelty of the lockdown likely led people to engage in increased information search, controlled and effortful information processing, and in-depth analysis and interpretation, as they did not possess established scripts and routines to guide their actions in this situation (Morgeson \& DeRue, 2006; Morgeson et al., 2015). Similarly, the lockdown was a highly disruptive event that did not allow employees to engage in ongoing habits and routines, but required changes in activities (e.g., working from home). Moreover, the lockdown likely led people to perceive a number of threats and challenges, such as increased work-family conflict 
(Rudolph et al., 2021). It was also a highly critical event that was salient to all organizations and employees in Germany and necessitated unusual attention and deployment of personal energy resources (Morgeson et al., 2015). Unlike “mega events" (e.g., elections, world championships), the lockdown was not planned, anticipated, or actively sought, but unexpected and aversive (i.e., like a natural disaster, terrorist attack). As employees likely did not possess behavioral scripts and resources to manage this novel, disruptive, and critical event, as well as various work- and nonwork-related changes associated with the lockdown, we assume that their task proficiency, adaptivity, and proactivity decreased between early April 2020 and early May 2020.

Moreover, based on event system theory, we argue that the lockdown had direct and wideranging "top-down" effects on work performance dimensions because it resided at a rather high hierarchical level (i.e., the country; Proposition 4 in Morgeson et al., 2015) and influenced a large number of lower hierarchical levels (i.e., organizations, teams, individuals; Proposition 5 in Morgeson et al., 2015). Finally, Morgeson (2015, Proposition 7) argued that strong events that last for a relatively long time are more likely to change employee behaviors than relatively short events. As the first lockdown in Germany lasted for more than four weeks, we expect that it significantly reduced work performance between the beginning of April 2020 and the beginning of May 2020. These assumptions are also consistent with crisis theory (Moos \& Tsu, 1976), which suggests that "people generally operate in consistent patterns, in equilibrium, with their environment, solving problems with minimal delay by habitual mechanisms and reactions. When the usual problem-solving mechanisms do not work, tension arises and feelings of discomfort and strain occur. The individual experiences anxiety, fear, guilt or shame, a feeling of helplessness, some disorganization of function, and possibly other symptoms" (p. 13; see also Schlossberg, 1981). 
A meta-analysis of 25 longitudinal studies and natural experiments with various samples including both employed and non-employed participants (total $N=72,004 ; 58$ effect sizes) found that lockdowns had small effects on mental health problems $(\rho=.17)$, and no significant effects on positive psychological functioning (Prati \& Mancini, 2021). So far, very few longitudinal studies have examined effects of lockdowns during the COVID-19 pandemic on experiences and behaviors of employees (e.g., Zacher \& Rudolph, 2021b). For example, a longitudinal study conducted between September 2019 and April 2020 found an overall decline in work satisfaction due to the first national lockdown in Germany, particularly among working mothers and among childless employees who had to switch to short-time work (Möhring et al., 2021). Another study conducted between January and May 2020 found general decreases in work engagement, increases in job satisfaction, as well as initial declines in work-nonwork balance, workload, and autonomy need satisfaction, followed by recovery patterns in May 2020 (Syrek et al., 2021). Finally, a study conducted between April and June 2020 showed that female employees with low partner support experienced higher levels of exhaustion during the lockdown in Germany (Meyer et al., 2021). The current study is the first to examine how a lockdown during the COVID-19 pandemic may have affected changes in different dimensions of work performance.

Hypothesis 1: Self-reported work performance (i.e., task proficiency, adaptivity, proactivity) declined due to the lockdown period in Germany between early April and early May 2020.

\section{Recovery of Self-Reported Work Performance after the Lockdown}

We further expect that employees' self-reported work performance increased (i.e., recovered) in the months following the lockdown in Germany (i.e., between early May 2020 and early September 2020; see Figure 1). Beginning in May 2020 and throughout the summer months, the governments of the 16 German states, after consultation with the federal government, gradually 
eased the restrictions that were in place during the lockdown. For instance, most daycares and schools re-opened during these months and employees were allowed to return to their worksites. We suggest that not only the lifting of restrictions may have contributed to increases in work performance, but also that employees adapted to the pandemic situation (e.g., adherence to new hygiene rules, such as wearing face masks).

The gradual recovery process after a strong event, which led to abrupt changes in experience or behavior, has been proposed by several transition theories (Bliese et al., 2017; Schlossberg, 1981). For example, in their crisis theory, Moos and Tsu (1976) suggested two phases of adaptation after a transition: "an acute phase in which energy is directed at minimizing the impact of the stress, and a reorganization phase in which the new reality is faced and accepted. In the acute period feelings may be denied while attention is directed to practical matters. [...] The reorganization phase involves the gradual return to normal functioning” (pp. 14-15). The transition framework based on the discontinuous growth model offers that the transition process due to an event (TRANS parameter) is followed by a recovery process (RECOV parameter), during which individuals reorganize themselves and return to normal functioning (Bliese et al., 2017). Based on these arguments, we hypothesize that employees' work performance recovered in the months after the lockdown.

Hypothesis 2: After the lockdown period in Germany, self-reported work performance (i.e., task proficiency, adaptivity, proactivity) increased between early May and early September 2020.

\section{The Role of Core Self-Evaluations}

A key tenet of transition theories is that the strength of the event's effects as well as subsequent recovery processes may depend on the level of relevant individual difference characteristics (Bliese et al., 2017; Morgeson et al., 2015). According to Schlossberg (1981), a 
wide variety of individual difference characteristics may influence the success or failure of adapting to a transition, including demographic characteristics, personal resources, coping strategies and self-management, as well as personality traits and "self-attitudes." The latter include "a moderately favorable self-evaluation, an internal locus of control (that is, the belief that one's actions have some causal relation to one's life), and a sense of responsibility. The importance of the first - a moderately favorable self-evaluation - is supported by research, which shows, for instance, that the maintenance of self-esteem and a sense of personal worth is important to survival under conditions of extreme stress ...” (Schlossberg, 1981, p. 12).

Based on Schlossberg's (1981) arguments regarding "self-attitudes" and research on beneficial effects of high levels of core self-evaluations in the work context (Judge, 2009; Kammeyer-Mueller et al., 2009), we focus on this individual difference characteristic in the current study. Core self-evaluations reflect employees' fundamental and favorable evaluations about themselves, their abilities, and their control (Judge, 2009). They are conceptualized as a relatively stable trait with a broad scope and evaluative focus (Judge et al., 1997). As a higherorder construct, core self-evaluations encompass four dimensions, including self-esteem, generalized self-efficacy, internal locus of control, and emotional stability (Judge et al., 2002). People with high core self-evaluations are confident in their abilities, feel in control of their lives, and see themselves as valuable beings (Judge et al., 2004). Research has shown positive relationships between core self-evaluations and several work outcomes, including job satisfaction, motivation, and work performance (Erez \& Judge, 2001; Judge \& Bono, 2001)

Similar to Schlossberg (1981), Bliese and colleagues (2017) argued that high or low levels of certain individual characteristics may contribute to resilience in the face of a strong event, because the experiences and behaviors of individuals with these characteristics may be less 
affected by the event (i.e., non-significant TRANS parameter). In addition, even if the outcomes of individuals with high levels in the individual difference characteristic may have declined due to the event, they might subsequently experience a more pronounced recovery (i.e., significant TRANS and RECOV parameters). Accordingly, we expect that employees with high (vs. low) core self-evaluations were better able to cope with the lockdown in Germany and, thus, were more likely to maintain their work performance between April and May 2020. Furthermore, we propose that employees with high (vs. low) core self-evaluations, if they experienced a decline in work performance dimensions due to the lockdown, experienced a more pronounced recovery in work performance in the months following the lockdown.

Hypothesis 3: High (vs. low) levels of core self-evaluations buffered the decline in selfreported work performance (i.e., task proficiency, adaptivity, proactivity) due to the lockdown period in Germany between early April and early May 2020.

Hypothesis 4: After the lockdown period in Germany, high (vs. low) levels of core selfevaluations strengthened the increase in self-reported work performance (i.e., task proficiency, adaptivity, proactivity) between early May and early September 2020.

\section{Method}

All data, $\mathrm{R}$ code to replicate the analyses, and complete results are available in our online appendix: https://osf.io/n2m79/

\section{Study Design, Participants, and Procedure}

Work performance was measured eight times, first at the beginning of December 2019 (Time [T] 1), then again at the beginnings of March (T2), April (T3), May (T4), June (T5), July (T6), August (T7), and September 2020 (T8; see Figure A1). Additionally, core self-evaluations were measured at $\mathrm{T} 1$. The data were collected as part of a larger longitudinal data collection effort. 
Three articles based on the same dataset, but with completely different research questions, have been published (Rudolph \& Zacher, 2021; Zacher \& Rudolph, 2021a, 2021b). A professional panel company was commissioned to recruit participants from a nationally representative online panel in Germany. The company is ISO 26362 certified, which ensures quality of the survey data. To be eligible to participate, participants had to be at least 18 years old and be working fulltime at each measurement wave. At T1, 4,839 persons in the company's database were contacted. Of these persons, 2,439 initiated the survey and provided at least partial responses (e.g., demographics, substantive variables; response rate of $38.19 \%$ ) to the T1 survey. Of these 2,439 persons, 591 provided complete responses at all eight time points.

To address systematic patterns of attrition, incomplete responders $(n=1,848)$ were compared to the panel of complete responders $(n=591)$ on key demographic and substantive variables. A summary of these comparisons can be found in Table A1 in the online appendix. To further address attrition, a binary logistic regression model was specified, predicting complete/incomplete respondent status (coded as $0=$ incomplete $; 1=$ complete) from these demographic and substantive variables; this model only explained $\mathrm{R}^{2}$ Cox \& Snell $=.031$ or $3.1 \%$ of the variance in attrition over time. Given the small amount of variance accounted for in this model, we are confident that attrition was not of principle concern in this study. Complete details of attrition analyses are available in our online appendix.

Participants' ages ranged from 21 to 69 years with a mean age of 45.20 years $(S D=10.60)$, and $36.70 \%$ were female. In terms of educational level, a majority held either intermediate secondary school/high school $(34.70 \%)$ or college/university or technical college diplomas (41.30\%). Additional details about participant demographics can be found in Table A1. 


\section{Measures}

\section{Work Performance.}

Task proficiency, adaptivity, and proactivity were assessed by self-report at all eight time points using three items each from Griffin and colleagues (2007). Participants were instructed to think about the past three months (T1 and T2) and the past month (T3-T8), respectively, in providing their ratings. Example items are "I carried out the core parts of my job well" (task proficiency), "I adapted well to changes in my core tasks" (adaptivity), and "I initiated better ways of doing my core tasks" (proactivity). The 7-point response scale ranged from $1=$ never to $7=$ always. Cronbach's alphas for each performance dimension ranged between $\alpha=.817-.910$ (task proficiency), $\alpha=.749-.842$ (adaptivity), and $\alpha=.875-.922$ (proactivity; see also Table A2 in the online appendix) across all eight time points.

\section{Core Self-Evaluations.}

We used a 12-item measure developed and validated by Judge et al. (2003) to assess core selfevaluations by self-report at T1 (December 2019). Of the 12 items, six are positively and six are negatively worded, and the latter items are reverse coded. An example item is "I am capable of coping with most of my problems." Responses were provided on a 7-point scale ranging from 1 $=$ not true at all to $7=$ very true. Cronbach's alpha for the scale was $\alpha=.90$.

\section{Work-Related Changes Due to the Lockdown.}

We used two items from the T4 survey (beginning of May 2020) in supplemental analyses (reported below) to better understand why work performance changed during to the lockdown period. First, we asked employees to rate the statement, "My everyday work life has changed significantly in the past four weeks due to the COVID-19 pandemic," using a response scale ranging from 1 (not true at all) to 5 (completely true). Second, we asked employees to respond to 
an open-ended question: "Please describe briefly how your everyday work life has changed in the past four weeks due to the COVID-19 pandemic." The first author and the third author coded the responses using four categories $(0=$ no work-related changes/no response, $1=$ neutral workrelated changes, $2=$ negative work-related changes, $3=$ positive work-related changes, $4=$ both negative and positive work-related changes). When participants described work-related changes but did not evaluate them in either positive or negative ways (e.g., "I started working from home"), the responses were coded as neutral work-related changes. Interrater reliability (Krippendorffs' alpha) was good, $\alpha_{\mathrm{K}}=.83$ (Hayes \& Krippendorff, 2007), and all discrepancies were resolved through discussion.

\section{Analytical Strategy}

All analyses were conducted in R, and statistical models were specified in a structural equation modeling framework using the `lavaan` package (Rosseel, 2012) with a robust maximum likelihood (MLR) estimator. We used unconditional and conditional discontinuous growth modeling to test our hypotheses; unconditional models were specified without exogenous predictors of work performance intercepts and slopes, whereas conditional models included T1 core-self evaluations as an exogenous predictor of work performance intercepts and slopes. To reduce model complexity, separate models were specified for each work performance dimension (i.e., task proficiency, adaptivity, proactivity). Following the advice of Bliese and Lang (2016), three slope parameters (i.e., TIME $E_{\text {pre, }}$ TRANS, and RECOV) were specified in each model to represent discontinuous growth. First, the TIME $_{\text {pre }}$ slope (parameterized as $[0,3,4,5,6,7,8,9]$ ) was specified to capture linear trajectories in work performance before the lockdown (i.e., parametrized to account for the spacing of December 2019 and March 2020 to September 2020). Second, the TRANS slope (parameterized as $[0,0,0,1,1,1,1,1]$ ) was specified to capture the 
hypothesized shift in work performance trajectories due to the lockdown between April 2020

(T3) and May 2020 (T4). Third, the RECOV slope (parameterized as [0, 0, 0, 0, 1, 2, 3, 4]) was specified to capture changes in work performance trajectories after the lockdown from May 2020 (T4) to September 2020 (T8).

According to Bliese and Lang (2016), these three slopes are understood in concert (see also Bliese et al., 2017). The TIME $E_{\text {pre }}$ slope represents the linear change process found in a typical growth model; however, with the addition of the TRANS and RECOV slopes, the TIME parameter estimate is understood as the pre-transition slope (i.e., changes from T1 to T3). The TRANS slope specifies "when" the change in work performance trajectories occurs (i.e., at T4), and its associated parameter estimate represents the degree to which the intercept changes after the transition. Finally, the RECOV slope represents the linear change in work performance following the transition (i.e., from T4 to T8), and its parameter estimate represents the degree to which the event modeled by TRANS alters the trajectory of the TIME $E_{\text {pre }}$ slope.

\section{Results}

\section{Intercorrelations, Measurement Invariance, and Confirmatory Factor Analyses}

Descriptive statistics and intercorrelations among study variables can be found in Table A2 in the online appendix. An important first step in modeling longitudinal relationships is to establish measurement invariance/equivalence over time. Thus, we specified a series of increasingly restrictive confirmatory factor analysis (CFA) models for each of the work performance dimensions. In summary of these models, metric invariance (i.e., equivalent factor loadings) was upheld (see online appendix for complete details and additional supporting measurement models).

We also specified a series of CFA models among T1 measures to demonstrate the ability to 
separately represent the three dimensions of work performance (i.e., task proficiency, adaptivity, and proactivity) and core self-evaluations. The fit of a four-factor model was not optimal $\left[\chi^{2}(183)\right.$ $=1644.441, p<.001, \mathrm{CFI}=.777, \mathrm{RMSEA}=.128, \mathrm{SRMR}=.119]$. However, it has been noted that negatively worded items often account for their own "method factor" in the measurement of core self-evaluations (Arias \& Arias, 2017). Including a negatively-worded item method factor (see Dalal \& Carter, 2015) in this model (i.e., 4 substantive factors +1 method factor) substantially increased the fit of the measurement model $\left[\chi_{(173)}^{2}=662.745, p<.001, \mathrm{CFI}=.924\right.$, $\mathrm{RMSEA}=.077, \mathrm{SRMR}=.060]$. Moreover, this five-factor model had a significantly better fit than a two-factor model (i.e., 1 substantive factor +1 method factor) $\left[\Delta \chi^{2}(9)=1937.300, p<\right.$ .001]. Thus, we are comfortable suggesting that the three work performance dimensions and core self-evaluations are empirically distinguishable.

\section{Hypothesis Tests}

Table A3 in the online appendix summarizes parameter estimates from the unconditional growth models, whereas Table 1 summarizes parameter estimates from the conditional growth models. Each of these models fit the data well (see Tables A3 and 1 and complete results in the online appendix).

\section{PLEASE INSERT TABLE 1 HERE}

Hypothesis 1 suggests that self-reported work performance declined between the beginning of April 2020 and the beginning of May 2020 due to the lockdown. Considering Table A3, evidence in support of this hypothesis comes from the transition slope parameters (i.e., $B_{\text {TRANS }}$ ). The transition slope parameters suggested significant negative transitions in task proficiency $\left(B_{\text {TRANS }}=-.134, S E=.040, p=.001\right)$ and proactivity $\left(B_{\text {TRANS }}=-.100, S E=.050, p=.045\right)$ between April 2020 and May 2020. In contrast, the transition slope parameter was not significant 
for adaptivity. Thus, Hypothesis 1 was partially supported. In addition, we also observed negative linear pre-transition slopes for adaptivity $\left(B_{\text {TIMEpre }}=-.057, S E=.011, p<.001\right)$ and proactivity $\left(B_{\text {TIMEpre }}=-.075, S E=.013, p<.001\right)$, suggesting that these dimensions of work performance already declined before the national lockdown in Germany. In contrast, the $\mathrm{TIME}_{\text {pre }}$ parameter was not significant for task proficiency.

According to Hypothesis 2, following the lockdown (i.e., between early May 2020 and early September 2020), self-reported work performance increased. Considering Table A3, evidence for this hypothesis comes from the recovery slope parameters (i.e., $B_{\text {RECOV }}$ ). Specifically, the recovery slope parameters for task proficiency $\left(B_{\mathrm{RECOV}}=.031, S E=.016, p=.046\right)$, adaptivity $\left(B_{\mathrm{RECOV}}=.060, S E=.018, p=.001\right)$, and proactivity $\left(B_{\mathrm{RECOV}}=.107, S E=.020, p<.001\right)$ were all significant and positive, suggesting positive recovery in the three work performance dimensions between May 2020 and September 2020. Thus, Hypothesis 2 was supported. Figure 2 graphically represents the discontinuous change trajectories of the three work performance dimensions.

\section{PLEASE INSERT FIGURE 2 HERE}

Hypothesis 3 suggested that core self-evaluations would buffer the decline in self-reported work performance due to the national lockdown in Germany between early April 2020 and early May 2020. Considering Table 1, evidence for this hypothesis comes from regressing the transition slope parameters (i.e., $B_{\text {TRANS }}$ ) onto T1 core self-evaluations. Contrary to this hypothesis, core self-evaluations did not predict the transition slope parameters for any work performance dimension. Thus, Hypothesis 3 was not supported. In addition, results showed that individual differences in core self-evaluations were positively associated with average levels (i.e., $B_{\text {INTERCEPT) }}$ of all three work performance dimensions (see Table 1). Moreover, core-self 
evaluations negatively predicted the negative pre-transition slope of adaptivity $\left(B_{\text {TIMEpre }}=-.034\right.$, $S E=.011, p=.002)$. This suggests that high core self-evaluations are associated with stronger declines in adaptivity in the months before the lockdown. Core self-evaluations did not significantly predict the pre-transition slopes of the other two work performance dimensions.

Finally, according to Hypothesis 4, core self-evaluations strengthen the increase in selfreported work performance after the lockdown in Germany between early May 2020 and early September 2020. Considering Table 1, evidence for this hypothesis comes from regressing the recovery slope parameters (i.e., $\left.B_{\text {RECOV}}\right)$ onto core self-evaluations. Core self-evaluations positively predicted recovery slope parameters for task proficiency $\left(B_{\mathrm{RECOV}}=.030, S E=.015, p\right.$ $=.049)$ and adaptivity $\left(B_{\mathrm{RECOV}}=.041, S E=.018, p=.021\right)$, but not for proactivity. Thus, Hypothesis 4 was partially supported. Figure 3 graphically represents the discontinuous change trajectories of the three work performance dimensions conditional upon core self-evaluations.

\section{PLEASE INSERT FIGURE 3 HERE}

\section{Supplemental Analyses}

We conducted two supplemental analyses to better understand the potential underlying mechanisms of declines in work performance during the lockdown. First, we examined the extent to which employees experienced work-related changes due the lockdown as a predictor of the work performance intercepts and slopes. Results showed that work-related changes due to the lockdown significantly predicted the transition slope parameters of task proficiency $\left(B_{\text {TRANS }}=-\right.$ $.082, S E=.033, p=.014)$, adaptivity $\left(B_{\text {TRANS }}=-.095, S E=.036, p=.009\right)$, and proactivity $\left(B_{\text {TRANS }}=-.131, S E=.040, p=.001\right)$. Complete results of this analysis are available in our online appendix (see Table A4). As depicted in Figure A2 in the online appendix, the work performance of employees who experienced greater work-related changes due to the lockdown 
declined, whereas the performance of employees who did not experience work-related changes remained stable.

Second, results of the qualitative data analysis (Table A5 in the online appendix) showed that most participants reported neutral work-related changes during the lockdown period (e.g., “working from home," without further qualifications). In addition, negative work-related changes were reported much more frequently than positive work-related changes, independent of the extent of work-related changes. Overall, results of these supplemental analyses suggest that more intense work-related changes due to the first national lockdown may be the underlying reason for the work performance declines during this transition period. Most of the work-related changes reported by participants were neutral or negative in nature. However, it remains an open question as to how, in addition to the intensity of the changes, the quality of the changes (i.e., negative, neutral, positive), or the ratio of positive to negative changes, may have played a role in explaining the work performance declines.

\section{Discussion}

The first aim of this study was to examine within-person changes in three dimensions of selfreported work performance across the early stages of the COVID-19 pandemic in Germany. Consistent with expectations based on event system and transition theories (Bliese et al., 2017; Morgeson et al., 2015), we found that task proficiency and proactivity, but not adaptivity, declined due to the national lockdown between early April and early May 2020 (i.e., transition effects). Moreover, we showed that all three work performance dimensions increased in the months following the lockdown, between early May and early September 2020 (i.e., recovery effects). In addition to these hypothesized effects, we also found that adaptivity and proactivity, but not task proficiency, decreased already in the months before the lockdown (i.e., pre-transition 
effects between early December 2019 and early April 2020). A possible explanation is that opportunities to demonstrate these behaviors at work became more constrained during the lead up to the lockdown (e.g., due to increased caution and social distancing). Thus, employees' levels of adaptivity and proactivity may have been more sensitive to the growing threat of the Sars-CoV-2 virus for their work even before the World Health Organization declared COVID-19 a pandemic in mid-March 2020.

Our second aim was to examine the role of individual differences in core self-evaluations for the predicted changes in work performance during the early stages of the COVID-19 pandemic. We found partial support for our hypotheses based on transition theories. Specifically, whereas high levels of core self-evaluations strengthened the recovery effects for all three dimensions of work performance, we did not find significant effects of core self-evaluations on the transition slopes. Thus, high levels of core self-evaluations benefited employees' resilience by strengthening the recovery process after the lockdown, but they did not buffer the immediate negative effects on work performance due to the lockdown. In addition, and consistent with previous research, we found that core self-evaluations were positively associated with the general levels of all three work performance dimensions (Erez \& Judge, 2001; Judge \& Bono, 2001). Finally, results showed that high levels of core self-evaluations exacerbated the decline in adaptivity in the months before the lockdown (i.e., pre-transition slope). Further theorizing and research is necessary to examine potential reasons for this unexpected finding.

\section{Theoretical and Practical Implications}

The findings of our study may have a number of implications for theory development on events and transition processes. First, results of our supplemental analyses using both quantitative and qualitative data on work-related changes due to the lockdown provided further 
insights on why work performance may have changed during this transition period. Specifically, the extent to which employees experienced work-related changes predicted the transition parameters for all three dimensions of work performance, such that greater work-related changes were associated with steeper declines in performance. These findings extend our assumptions grounded in event system theory (Morgeson et al., 2015), based on which we characterized the lockdown as a highly novel, disruptive, and critical event that grasps employees' attention, impacts their cognitive processing, and challenges their established behavioral routines. Our supplemental results suggest that more intense work-related changes due to the lockdown may have impacted these cognitive-behavioral mechanisms which, in turn, resulted in temporary declines in work performance.

Future theoretical development should focus on more specific work- and nonwork-related mechanisms of these transition effects, the interplay between the intensity and the quality (i.e., negative, neutral, positive) of work-related changes employees experienced during the lockdown period, as well as potential accumulation effects of events on employee experiences and behavior. Specifically, such theorizing could explain under which conditions effects are stronger or weaker, and whether repeated lockdowns are associated with additional and reversible or irreversible declines in work performance. Future theorizing could also attempt to explain differential effects for the three work performance dimensions. We included task proficiency, adaptivity, and proactivity to replicate findings across multiple important dimensions of work performance. Future theory development and research on the underlying mechanisms may be helpful to better understand why we observed pre-lockdown and general lockdown effects for some, but not for all work performance dimensions.

Second, our findings suggest that core self-evaluations impact on performance recovery after 
a lockdown, but may not be effective with regard to mitigating the effects of the transition itself. It seems likely that other personal resources may have also been beneficial for coping with the lockdown and its aftermath. Accordingly, future theory development could develop a taxonomy of personal resources that distinguishes between generally beneficial resources and more essential "key resources" for dealing with strong events. Such a taxonomy could be very useful for researchers and practitioners aiming to assess and strengthen personal resources during transition and recovery processes.

In terms of practical implications, our findings suggest that organizations and employees should be aware of and prepared for the possibility that major events, such as the first lockdown due to the COVID-19 pandemic in Germany, can lead to decreases in task proficiency, adaptivity, and proactivity. Managers could provide additional support to their employees during this time, and employees might benefit from using self-management strategies to maintain their performance, such as selection, optimization, and compensation strategies (Moghimi et al., 2017). Furthermore, organizations could select for and attempt to strengthen employees' core self-evaluations, as this characteristic was generally positively related to work performance during the early stages of the pandemic and strengthened the recovery of performance in the months following the lockdown. Scholars have argued that core self-evaluations can be improved through cognitive-behavioral interventions (Judge et al., 1997). These interventions entail the use of psychological techniques to build self-efficacy, and techniques to modify dysfunctional thinking processes by which people evaluate their life experiences and reach conclusions about themselves. For example, techniques such as facilitating mastery experiences can enhance self-efficacy (Bandura, 1997). Cognitive restructuring techniques can be used to change dysfunctional thinking processes, such as overgeneralizing, irrational perfectionism, or 
desire for social approval (Beck et al., 1979).

\section{Limitations and Future Research}

Our study has a number of limitations that could be addressed in future research. First, we assessed the three work performance dimensions using employee self-reports. Scholars have questioned the validity of self-reported work performance, as employees have been shown to inflate their ratings (i.e., leniency bias), and self-reported work performance is only moderately positively correlated to supervisor- and peer-reported work performance (Harris \& Schaubroeck, 1988; Heidemeier \& Moser, 2009). Indeed, the average work performance scores observed in our study were all well above the mid-point of the scales (i.e., > 4 on a 7-point scale). However, it could be argued that leniency bias may be less of a concern in a longitudinal study, as the focus is on within-person changes in self-reported work performance over time. Thus, even if participants provided inflated ratings, they acted as their own "control group." Moreover, it could be argued that employees are generally in a better position to observe their own behavior at work than their supervisors or peers, who may not always be present. Nevertheless, we recommend that future research obtains work performance data from multiple sources (e.g., self, supervisor, peers, objective performance data). Such research could also help explain why self-rated work performance changed during the early stages of the COVID-19 pandemic, and why high levels of core self-evaluations may be beneficial in this context. Self-ratings of work performance may be influenced by a number of different factors residing at the between- and within-person levels, including objective productivity, individual traits and states (e.g., core self-evaluations, motives, positive and negative affect), and situational characteristics (e.g., performance appraisal vs. research study; Campbell \& Wiernik, 2015). While we cannot disentangle these influences with our study design, future studies could explore lockdown effects particularly on the various 
dynamic, within-person factors underlying self-rated work performance.

Second, we did not empirically examine the potential underlying reasons for the recovery effects in work performance following the lockdown suggested by transition theories (Bliese et al., 2017) and observed in our study. Based on transition theories, we assumed that work performance recovered because many restrictions were relaxed following the lockdown (e.g., schools and businesses reopened), and also because employees adapted to "the new normal." The latter explanation may be more likely than the former, as many work-related aspects did not change following the first lockdown in Germany (e.g., physical distancing, working from home). Adaptation processes may thus explain why we observed recovery in work performance instead of permanently lowered performance. For instance, employees may have learned how to work more effectively from home or how to comply with new hygiene rules at work. Consistently, research suggests that employees viewed the COVID-19 pandemic as less stressful in the months following the lockdown than during the lockdown (Zacher \& Rudolph, 2021a). Future research could examine the lifting of restrictions and adaptation to changes as two potential explanations of recovery patterns in work performance.

Finally, we focused on task proficiency, adaptivity, and proactivity, but not on other potentially important dimensions of work performance that may have changed due to the lockdown. For example, work and organizational psychologists have distinguished task, citizenship, and counterproductive performance (Campbell \& Wiernik, 2015). For instance, it may be possible that counterproductive performance declined among employees who worked from home. Similarly, our choice of core self-evaluations as the focal individual difference variable may be criticized. Some researchers have questioned the construct validity of core selfevaluations (Johnson et al., 2008). In addition, other individual difference variables may be 
considered relevant during a lockdown as well, for instance extraversion (Zacher \& Rudolph, 2021a) or coping strategies (Zacher \& Rudolph, 2021b). Nevertheless, consistent with

Schlossberg (1981) and Judge (2009), we argue that core self-evaluations represent an individual difference characteristics that is highly relevant in the context of transitions and work. Future research should consider core self-evaluations along with other individual differences (e.g., demographics, personality, coping strategies) as well as contextual characteristics (e.g., work demands and resources, such as job autonomy and social support, family characteristics, human resource management practices, national social safety net).

\section{Conclusion}

This study contributes to theory and research on events and transition processes by showing that the first national lockdown in Germany due to the COVID-19 pandemic led to declines in self-reported work performance between early April and early May 2020, and especially so among employees who experienced more intense work-related changes during this period. In addition, following the lockdown, work performance increased between early May 2020 and early September 2020. High levels of core self-evaluations strengthened these recovery processes for task proficiency and adaptivity. Overall, these findings imply that the lockdown was a novel, disruptive, and critical event that may have led to declines in important dimensions of work performance. Moreover, employees' self-rated work performance can recover from the negative impact of such an event, particularly if employees have high core self-evaluations.

\section{Open Data and Materials}

All data, $\mathrm{R}$ code to replicate the analyses, and complete results are available in our online appendix: https://osf.io/n2m79/?view_only=eb32691880db4f199cef2ff9ad03861e 


\section{References}

Arias, V. B., \& Arias, B. (2017). The negative wording factor of Core Self-Evaluations Scale (CSES): Methodological artifact, or substantive specific variance? Personality and Individual Differences, 109, 28-34. https://doi.org/10.1016/j.paid.2016.12.038

Asgari, E., Hunt, R. A., Lerner, D. A., Townsend, D. M., Hayward, M. L. A., \& Kiefer, K. (2021). Red giants or black holes? The antecedent conditions and multi-level impacts of star performers. Academy of Management Annals, 15, 223-265. https://doi.org/10.5465/annals.2019.0061

Bacharach, S. B., \& Bamberger, P. A. (2007). 9/11 and New York City firefighters' post hoc unit support and control climates: A context theory of the consequences of involvement in traumatic work-related events. Academy of Management Journal, 50, 849-868. https://doi.org/10.5465/amj.2007.26279180

Bandura, A. (1997). Self-efficacy: The exercise of control. W. H. Freeman.

Beck, A. T., Rush, A. J., Shaw, B. F., \& Emery, G. (1979). Cognitive therapy of depression. Guilford Press.

Bliese, P. D., Adler, A. B., \& Flynn, P. J. (2017). Transition processes: A review and synthesis integrating methods and theory. Annual Review of Organizational Psychology and Organizational Behavior, 4, 263-286. https://doi.org/10.1146/annurev-orgpsych-032516113213

Bliese, P. D., \& Lang, J. W. (2016). Understanding relative and absolute change in discontinuous growth models: Coding alternatives and implications for hypothesis testing. Organizational Research Methods, 19, 562-592. https://doi.org/10.1177/1094428116633502

Campbell, J. P., \& Wiernik, B. M. (2015). The modeling and assessment of work performance. 
Annual Review of Organizational Psychology and Organizational Behavior, 2, 47-74. https://doi.org/10.1146/annurev-orgpsych-032414-111427

Dalal, D. K., \& Carter, N. T. (2015). Negatively worded items negatively impact survey research. In C. Lance \& R. Vandenberg (Eds.), More statistical and methodological myths and urban legends: Doctrine, verity and fable in organizational and social sciences (pp. 112-132). Routledge.

Dalal, R. S., Bhave, D. P., \& Fiset, J. (2014). Within-person variability in job performance: A theoretical review and research agenda. Journal of Management, 40, 1396-1436. https://doi.org/10.1177/0149206314532691

Erez, A., \& Judge, T. A. (2001). Relationship of core self-evaluations to goal setting, motivation, and performance. Journal of Applied Psychology, 86, 1270-1279. https://doi.org/10.1037/0021-9010.86.6.1270

Griffin, M. A., Neal, A., \& Parker, S. K. (2007). A new model of work role performance: Positive behavior in uncertain and interdependent contexts. Academy of Management Journal, 50, 327-347. https://doi.org/10.5465/AMJ.2007.24634438

Harris, M. M., \& Schaubroeck, J. (1988). A meta-analysis of self-supervisor, self-peer, and peersupervisor ratings. Personnel Psychology, 41, 43-62. https://doi.org/10.1111/j.17446570.1988.tb00631.x

Hartmann, S., Weiss, M., Newman, A., \& Hoegl, M. (2020). Resilience in the workplace: A multilevel review and synthesis. Applied Psychology, 69, 913-959. https://doi.org/10.1111/apps.12191

Hayes, A. F., \& Krippendorff, K. (2007). Answering the call for a standard reliability measure for coding data. Communication Methods and Measures, 1, 77-89. 
https://doi.org/10.1080/19312450709336664

Heidemeier, H., \& Moser, K. (2009). Self-other agreement in job performance ratings: A metaanalytic test of a process model. Journal of Applied Psychology, 94, 353-370. https://doi.org/10.1037/0021-9010.94.2.353

Hochwarter, W. A., Laird, M. D., \& Brouer, R. L. (2008). Board up the windows: The interactive effects of hurricane-induced job stress and perceived resources on work outcomes. Journal of Management, 34, 263-289. doi.org/10.1177/0149206307309264

Johnson, R. E., Rosen, C. C., \& Levy, P. E. (2008). Getting to the core of core self-evaluation: A review and recommendations. Journal of Organizational Behavior, 29, 391-413. https://doi.org/10.1002/job.514

Judge, T. A. (2009). Core self-evaluations and work success. Current Directions in Psychological Science, 18, 58-62. https://doi.org/10.1111/j.1467-8721.2009.01606.x

Judge, T. A., \& Bono, J. E. (2001). Relationship of core self-evaluations traits—self-esteem, generalized self-efficacy, locus of control, and emotional stability — with job satisfaction and job performance: A meta-analysis. Journal of Applied Psychology, 86, 80-92. https://doi.org/10.1037/0021-9010.86.1.80

Judge, T. A., Erez, A., Bono, J. E., \& Thoresen, C. J. (2002). Are measures of self-esteem, neuroticism, locus of control, and generalized self-efficacy indicators of a common core construct? Journal of Personality and Social Psychology, 83, 693-710. https://doi.org/10.1037/0022-3514.83.3.693

Judge, T. A., Erez, A., Bono, J. E., \& Thoresen, C. J. (2003). The Core Self-Evaluations Scale (CSES): Development of a measure. Personnel Psychology, 56, 303-331. https://doi.org/10.1111/j.1744-6570.2003.tb00152.x 
Judge, T. A., \& Hurst, C. (2008). How the rich (and happy) get richer (and happier): Relationship of core self-evaluations to trajectories in attaining work success. Journal of Applied Psychology, 93, 849-863. https://doi.org/10.1037/0021-9010.93.4.849

Judge, T. A., Locke, E. A., \& Durham, C. C. (1997). The dispositional causes of job satisfaction: A core evaluations approach. Research in Organizational Behavior, 19, 151-188.

Judge, T. A., Van Vianen, A. E., \& De Pater, I. E. (2004). Emotional stability, core selfevaluations, and job outcomes: A review of the evidence and an agenda for future research. Human Performance, 17, 325-346. https://doi.org/10.1207/s15327043hup1703_4

Kammeyer-Mueller, J. D., Judge, T. A., \& Scott, B. A. (2009). The role of core self-evaluations in the coping process. Journal of Applied Psychology, 94, 177-195. https://doi.org/10.1037/a0013214

Meyer, B., Zill, A., Dilba, D., Gerlach, R., \& Schumann, S. (2021). Employee psychological well-being during the COVID-19 pandemic in Germany: A longitudinal study of demands, resources, and exhaustion. International Journal of Psychology. https://doi.org/10.1002/ijop.12743

Moghimi, D., Zacher, H., Scheibe, S., \& Von Yperen, N. W. (2017). The selection, optimization, and compensation model in the work context: A systematic review and meta-analysis of two decades of research. Journal of Organizational Behavior, 38, 247-275. https://doi.org/10.1002/job.2108

Möhring, K., Naumann, E., Reifenscheid, M., Wenz, A., Rettig, T., Krieger, U., \& Blom, A. G. (2021). The COVID-19 pandemic and subjective well-being: longitudinal evidence on satisfaction with work and family. European Societies, 23, S601-S617. https://doi.org/10.1080/14616696.2020.1833066 
Moos, R. H., \& Tsu, V. D. (1976). Human competence and coping: An overview. In R. H. Moos (Ed.), Human adaptation (pp. 3-16). Heath.

Morgeson, F. P. (2005). The external leadership of self-managing teams: Intervening in the context of novel and disruptive events. Journal of Applied Psychology, 90, 497-508. https://doi.org/10.1037/0021-9010.90.3.497

Morgeson, F. P., \& DeRue, D. S. (2006). Event criticality, urgency, and duration: Understanding how events disrupt teams and influence team leader intervention. The Leadership Quarterly, 17, 271-287. https://doi.org/10.1016/j.leaqua.2006.02.006

Morgeson, F. P., Mitchell, T. R., \& Liu, D. (2015). Event system theory: An event-oriented approach to the organizational sciences. Academy of Management Review, 40, 515-537. https://doi.org/10.5465/amr.2012.0099

Ng, T. W. H., \& Feldman, D. C. (2010). Human capital and objective indicators of career success: The mediating effects of cognitive ability and conscientiousness. Journal of Occupational and Organizational Psychology, 83, 207-235. https://doi.org/10.1348/096317909X414584

Prati, G., \& Mancini, A. D. (2021). The psychological impact of COVID-19 pandemic lockdowns: A review and meta-analysis of longitudinal studies and natural experiments. Psychological Medicine, 51, 201-211. https://doi.org/10.1017/S0033291721000015

Rosseel, Y. (2012). lavaan: An R package for structural equation modeling. Journal of Statistical Software, 48, 1-36. https://doi.org/10.18637/jss.v048.i02

Rudolph, C. W., Allan, B., Clarke, M., Hertel, G., Hirschi, A., Kunze, F., Shockley, K., Shoss, M., Sonnentag, S., \& Zacher, H. (2021). Pandemics: Implications for research and practice in industrial and organizational psychology. Industrial and Organizational Psychology: 
Perspectives on Science and Practice, 14(1-2), 1-35. doi:10.1017/iop.2020.48

Rudolph, C. W. \& Zacher, H. (2021, in press). Family demands and satisfaction with family life during the COVID-19 pandemic. Couple and Family Psychology: Research and Practice. doi: $10.1037 / \mathrm{cfp} 0000170$

Schlossberg, N. K. (1981). A model for analyzing human adaptation to transition. The Counseling Psychologist, 9, 2-18. https://doi.org/10.1177/001100008100900202

Syrek, C., Kühnel, J., Vahle-Hinz, T., \& de Bloom, J. (2021). Being an accountant, cook, entertainer and teacher-all at the same time: Changes in employees' work and work-related well-being during the coronavirus (COVID-19) pandemic. International Journal of Psychology. https://doi.org/10.1002/ijop.12761

Zacher, H., \& Rudolph, C. W. (2021a). Big Five Traits as predictors of perceived stressfulness of the COVID-19 pandemic. Personality and Individual Differences, 175, 110694. https://doi.org/10.1016/j.paid.2021.110694

Zacher, H., \& Rudolph, C. W. (2021b). Individual differences and changes in subjective wellbeing during the early stages of the COVID-19 pandemic. American Psychologist, 76, 50-62. https://doi.org/10.1037/amp0000702 
Table 1

Summary of Conditional Discontinuous Growth Models with Core Self-Evaluations

\begin{tabular}{|c|c|c|c|c|c|c|c|c|}
\hline Variable & Outcome & $R^{2}$ & Estimate & SE & $\mathbf{Z}$ & p-value & CI Lower & CI Upper \\
\hline \multirow[t]{4}{*}{ Task Proficiency } & $B_{\text {INTERCEPT }}$ & 0.206 & .329 & .036 & 9.062 & $<.001$ & .258 & .400 \\
\hline & $B_{\text {TIMEpre }}$ & 0.001 & -.004 & .009 & -.395 & .693 & -.022 & .015 \\
\hline & $B_{\text {TRANS }}$ & $<0.001$ & .005 & .042 & .115 & .908 & -.078 & .087 \\
\hline & $B_{R E C O V}$ & 0.015 & .030 & .015 & 1.968 & .049 & .000 & .060 \\
\hline \multirow[t]{4}{*}{ Adaptivity } & $B_{\text {INTERCEPT }}$ & 0.282 & .407 & .039 & 10.528 & $<.001$ & .331 & .482 \\
\hline & $B_{\text {TIMEpre }}$ & 0.076 & -.034 & .011 & -3.036 & .002 & -.056 & -.012 \\
\hline & $B_{\text {TRANS }}$ & 0.007 & .045 & .050 & .901 & .367 & -.053 & .142 \\
\hline & $B_{R E C O V}$ & 0.024 & .041 & .018 & 2.317 & .021 & .006 & .076 \\
\hline \multirow[t]{4}{*}{ Proactivity } & $B_{I N T E R C E P T}$ & 0.028 & .155 & .053 & 2.937 & .003 & .051 & .258 \\
\hline & $B_{\text {TIMEpre }}$ & 0.041 & -.028 & .014 & -1.964 & .050 & -.055 & .000 \\
\hline & $B_{\text {TRANS }}$ & 0.032 & .071 & .054 & 1.309 & .191 & -.035 & .177 \\
\hline & $B_{R E C O V}$ & 0.008 & .023 & .021 & 1.089 & .276 & -.018 & .065 \\
\hline
\end{tabular}

Note. Model fit statistics: Task Proficiency, $\chi^{2}(33)=88.920, p<.001, \mathrm{CFI}=.948, \mathrm{RMSEA}=.081, \mathrm{SRMR}=.059 ;$ Adaptivity, $\chi^{2}(33)=65.057, p=$ $.001, \mathrm{CFI}=.971, \mathrm{RMSEA}=.055, \mathrm{SRMR}=.041$; Proactivity, $\chi^{2}{ }_{(33)}=48.942, p=.037, \mathrm{CFI}=.990, \mathrm{RMSEA}=.034, \mathrm{SRMR}=.036 . R^{2}$ values represent variance explained in endogenous slopes and intercepts by exogenous core self-evaluations. 
Figure 1. Hypothesized Pre-Transition, Transition, and Post-Transition Trajectories in Work Performance (based on Bliese et al., 2017).

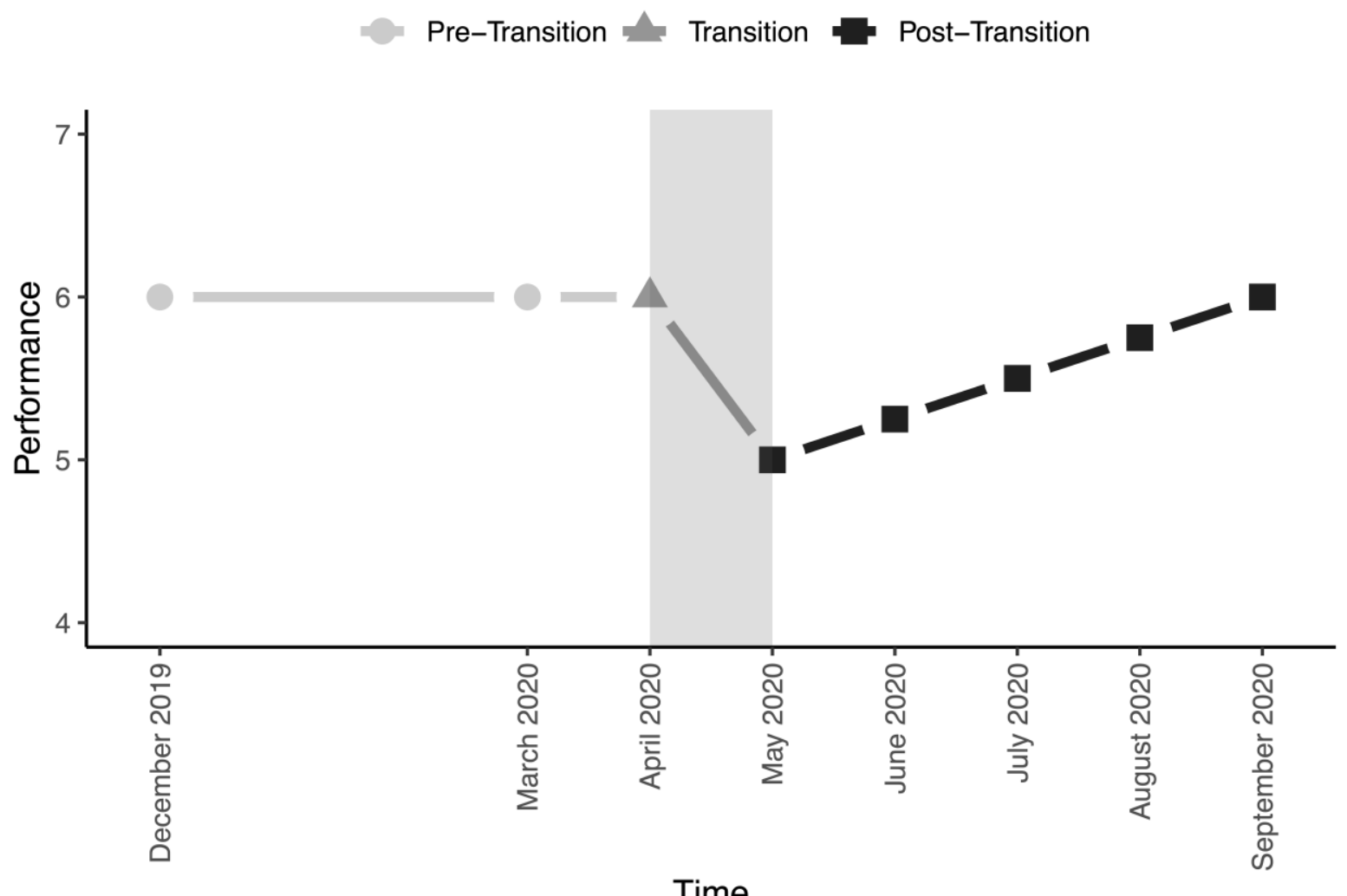

Time 
Figure 2. Predicted Trajectories in Task Proficiency, Adaptivity, and Proactivity for Unconditional Discontinuous Latent Growth Curve Models.
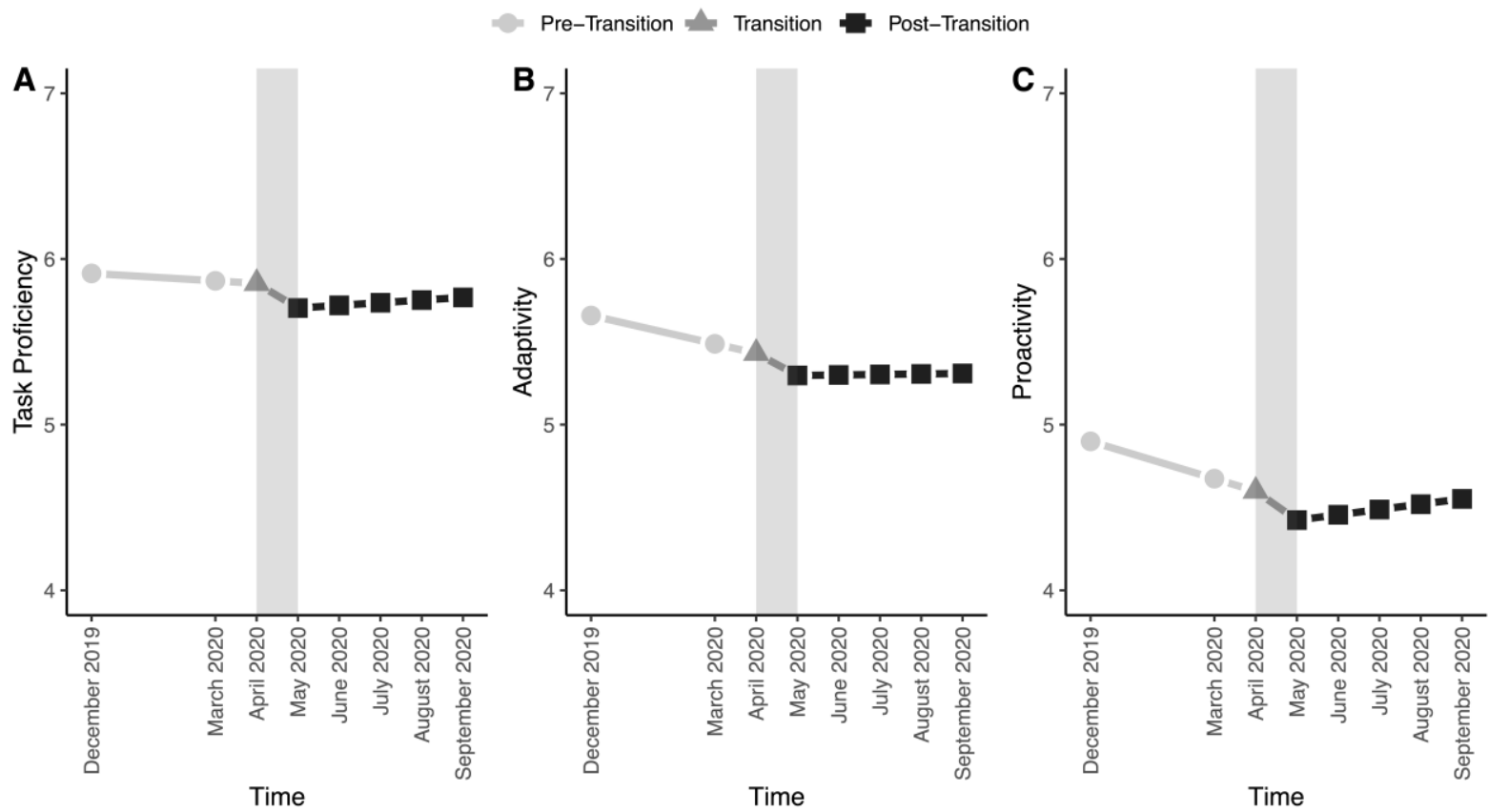

Note: The grey shaded region on each plot represents the transition event (i.e., the national lockdown in Germany). 
Figure 3. Predicted Trajectories in Task Proficiency, Adaptivity, and Proactivity for Conditional Discontinuous Latent Growth Curve Models with Core Self-Evaluations.

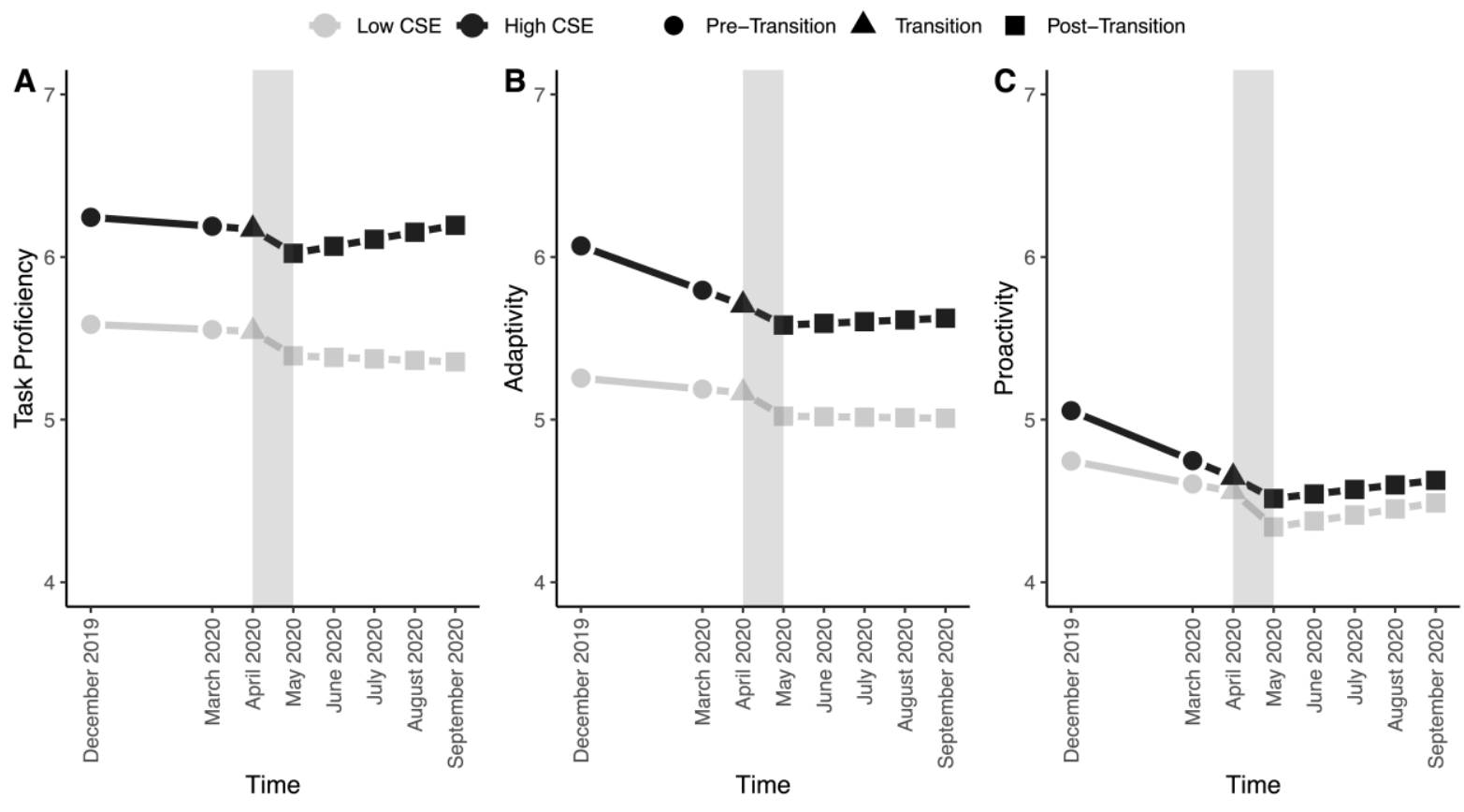

Note: The grey shaded region on each plot represents the transition event (i.e., the national lockdown in Germany). Low (high) core self-evaluations (CSE) $=+1 S D(-1 S D)$ from the mean. 